\title{
Study on the Analysis Method for Ship Maintenance Safety
}

\author{
Jun GONG \& Tao HU \\ Naval Univ. of Engineering, Wuhan, China \\ Leiqiang SUN \\ Navy Military Representative Office in Dalian Region, Dalian, 116041, China
}

\begin{abstract}
Considering the characteristics of ship maintenance, the causes for accident are further analyzed based on the theories of accident causation and hazard, so as to propose a concept of safety accident causation factor. A ship maintenance safety analysis framework is created as the basis for traceability analysis to unearth the root causes for accident, in order to develop effective preventive strategies and corrective actions, further reduce the risks of maintenance and prevent safety accident.
\end{abstract}

KEYWORD: Traceability analysis; causation factor; root cause; ship; maintenance

\section{INTRODUCTION}

Nowadays, safety accidents occur frequently during ship maintenance, resulting in economic losses and personal injury. Most of the existing safety analysis methods focus on hazard identification and causation of faults, errors or accidents, etc. to ascertain what causes safety incidents. However, ship is featured by long service life and increasingly complicated equipment, so these methods cannot be well applied in the safety analysis of ship maintenance or achieve very noticeable effect. Based on the characteristics of ship maintenance, this paper puts forward a safety analysis method to further improve the safety management of ship maintenance and effectively reduce the occurrence of safety accidents.

\section{FRAMEWORK DESIGN FOR SAFETY ANALYSIS OF SHIP MAINTENANCE}

As revealed in the analysis on accident causation theory [1], an accident is caused by multiple factors, which can be categorized into the motions of people and objects. When the orbits of people and objects intersect with each other, an accident may occur. Also, the motions of people and objects happen under a certain envrionment. Therefore, it is necessary, for the safety management of ship maintenance, track the unsafe behaviors of people and the unsafe states of objects, and combine it with the analysis of environment, in order to study the motion characteristics of people and objects and analyze the impacts of environment on the unsafe behaviors of people and the unsafe states of objects.

In the meanwhile, the occurrence of safety incident results from the joint effect of three hazards based on the analysis of hazard theory[2-3]. The first hazard is energy carrier or energy source; the second hazard is the fault and physical environmental factors of objects (including safety facilities) and the mistakes in the behaviors of individuals; the third hazard is the organizational factors that do not comply with safety requirements (organizational procedure, organizational culture, rules and systems, etc.), including organizer's unsafe behaviors and mistakes, etc. During the occurrence and expansion of safety incident, these three hazards depend on and foster each other to jointly cause a hazard accident.

Therefore, the safety incident of ship maintenance is actually caused by human factor, object factor and environmental factor. Human factor refers to the factor that causes the safety incident of ship maintenance and relates to people. Object factor refers to the unsafe state of object that causes the safety incident of ship maintenance. The unsafe state of object is a state of fault. The fault of object may cause the failure of measures for constraining or restricting energy or dangerous matters, e.g. any electric leakage caused by damaged insulation of electric wire and damage to machine as a result of pipe rupture, etc. Environmental factor refers to the factor that causes the safety incident of ship maintenance in the environment.

There are not only various relations among human, object and environmental factors, but also the causal relations among causation factors. Hence, 
safety incident is caused for multiple reasons. In other words, the causation analysis on the safety incident of ship maintenance should not simply blame "violation of rules" or "carelessness", but delve into the nature of phenomenon and trace the causes at deeper level based on superficial causes, so as to find out the complicated logical and causal relations among causation factors till the root cause is exposed. Only in this way, it is possible to thoroughly identify hazardous factors and discover the effective ways to control dangers.

Based on the above analysis, the safety analysis framework of ship maintenance can be obtained. In other words, a cause is selected as the effect after analyzing the possible general causes and specific causes in the "cause list of causation model". The possible cause is discovered through analyzing the "effect-cause linked list" for the taxonomic group containing the said cause, and it may be taken as the effect to analyze and discover the possible cause. In this way, the root cause can be discovered through the analysis in the end. The outcome of traceability analysis is an effect-cause link for each branch. The last cause of link is the possible root cause of the safety incident. Therefore, the logical and causal relations at deeper level among causation factors can be obtained through analysis. The specific analysis framework is presented in Fig. 1.

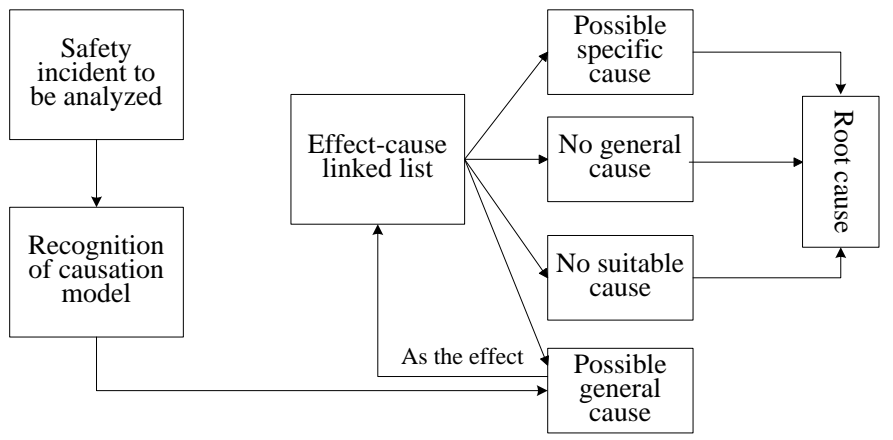

Fig. 1 Safety Analysis Framework of Ship Maintenance

\section{CLASSIFICATION OF CAUSATION MODELS AND CAUSES}

\subsection{Classification of Causation Models}

The external appearance of safety incident is defined as the causation model. The causation models for human factor, object factor and environmental factor are defined as human factor causation model, object factor causation model and environmental factor causation model respectively. Based on the analysis of the factors affecting ship maintenance, such three causation models are classified and defined as presented in Table 1.

Table 1. Margin settings for A4 size paper and letter size paper.

\begin{tabular}{|c|c|c|}
\hline \multicolumn{2}{|c|}{ Causation Model } & Definition/Interpretation \\
\hline \multirow{4}{*}{$\begin{array}{c}\text { Human Factor } \\
\text { Causation } \\
\text { Model }\end{array}$} & Negligence & Lose attention; be disturbed; overlook warnings, etc. \\
\hline & Omission & Operate with omitted item, forget operation, etc. \\
\hline & Wrongness & Wrong understanding, wrong objective, wrong operation and improper operation, etc. \\
\hline & Violation & Maintain against procedures and related provisions, etc. \\
\hline \multirow{3}{*}{$\begin{array}{l}\text { Object Factor } \\
\text { Causation } \\
\text { Model }\end{array}$} & Equipment Defects & Safety incident due to the problems of equipment, machine and software in use \\
\hline & Tool Defects & Safety incident due to the problems of tool in use \\
\hline & Energy Transfer & $\begin{array}{l}\text { Energy transfer of dangerous matters due to radiation, explosion, electric strike, } \\
\text { combustion and high temperature, etc. }\end{array}$ \\
\hline \multirow{3}{*}{$\begin{array}{l}\text { Environmental } \\
\text { Factor Causation } \\
\text { Model }\end{array}$} & Hostile Environment & $\begin{array}{l}\text { Poor natural environment or working environment, and abrupt environmental } \\
\text { changes, etc. }\end{array}$ \\
\hline & $\begin{array}{l}\text { Organizational } \\
\text { Impacts }\end{array}$ & $\begin{array}{l}\text { Improper organizational management; wrong decision; defect in team building; lack } \\
\text { of safety culture, etc. }\end{array}$ \\
\hline & Defective Information & No or unreasonable supporting information including procedures and systems, etc. \\
\hline
\end{tabular}

\subsection{Classification of Causes}

The basic reason for safety incident is called cause. In the work of ship maintenance, the reasons for safety incident are classified into people-related causes, object-related causes and environmentrelated causes. Among them, people-related causes include: A. State of hardware, B. Psychological factors and C. Quality factors. Object-related causes include: D. Equipment defects, E. Tool defects and F. Energy transfer; environment-related causes are classified into ten types, namely, G. Working environment unsuitable for maintenance, $\mathrm{H}$. Improper arrangement of tasks, I. Safety culture, J. Training, K. Supervision management, L. Leadership, M. Decision-making, N. Team building. The 16 types of causes are regarded as the taxonomic groups, which are represented alphabetically. Each group is further segmented into several causes. The names and codes of causes are shown in Table 2. 
Table 2. Classification of Causes.

\begin{tabular}{|c|c|c|}
\hline Code & Name & Description \\
\hline A1 & Improper physiological factors & $\begin{array}{l}\text { Diseases, psychological or mental disorder, alcohol poisoning, taking drugs, } \\
\text { and other factors affecting the level of consciousness }\end{array}$ \\
\hline $\mathrm{A} 2$ & Poor physical conditions & Poor health conditions, tiredness and other poor physical conditions \\
\hline B1 & Negative psychological factors & $\begin{array}{l}\text { Negative motive of work, poor psychological bearing ability, nerve, ignorance, } \\
\text { blind pursuit, conformity, rebellion and other psychological conditions }\end{array}$ \\
\hline $\mathrm{C} 1$ & Lack of knowledge and skills & Lack of professional knowledge, operating skills and work experience, etc. \\
\hline $\mathrm{C} 2$ & Bad attitude toward work and habits & Lack of sense of responsibility, bad habits and lack of safety uality, etc. \\
\hline D1 & Fatal equipment fault & Equipment cannot function normally due to fatal fault \\
\hline D2 & Equipment aging & $\begin{array}{l}\text { Delay in equipment maintenance, low working efficiency and other potential } \\
\text { safety hazards }\end{array}$ \\
\hline E1 & Insufficient protection & Insufficient or defective protective devices \\
\hline E2 & Improper use of tools & $\begin{array}{l}\text { Mainly include aging, expiration or delayed replacement of tools for } \\
\text { maintenance, etc. }\end{array}$ \\
\hline F1 & Energy transfer & Dangers caused by radiation, explosion, electric strike and pollution, etc. \\
\hline G1 & Poor environmental quality & $\begin{array}{l}\text { Temperature, humidity, dust, noise, vibration, radiation and poisonous } \\
\text { substances, etc. }\end{array}$ \\
\hline G2 & Lack of safety warnings & $\begin{array}{l}\text { No, obscure, unclear or misguiding signs including safety operating } \\
\text { procedures and warnings, etc. }\end{array}$ \\
\hline H1 & Improper arrangement of task/operation & $\begin{array}{l}\text { Excessive workload, long-term operation, change of operation or start of new } \\
\text { operation and shift change, etc. }\end{array}$ \\
\hline I1 & Lack of safety culture & $\begin{array}{l}\text { Leaders lack the knowledge of and attitude toward safety culture, people's } \\
\text { weak awareness of and attitude toward safety, lack of continual improvement } \\
\text { in safety culture, etc. }\end{array}$ \\
\hline $\mathrm{J} 1$ & $\begin{array}{l}\text { Lack of training about knowledge and } \\
\text { skills }\end{array}$ & $\begin{array}{l}\text { Lack of training about professional knowledge and operating skills; lack of } \\
\text { training after equipment change }\end{array}$ \\
\hline $\mathrm{J} 2$ & Lack of safety training & $\begin{array}{l}\text { No cultivation of people's awareness of and attitude toward safety and no } \\
\text { good team safety culture }\end{array}$ \\
\hline $\mathrm{K} 1$ & Loose supervision and management & $\begin{array}{l}\text { Insufficient fairness and completeness of supervision system; poor execution } \\
\text { of supervision and management }\end{array}$ \\
\hline L1 & Defective organizational structure & $\begin{array}{l}\text { Unreasonable organizational structure; unclear scope of authority; unclear } \\
\text { responsibility, etc. }\end{array}$ \\
\hline M1 & Decision-making mistakes & Unreasonable allocation of tasks and unscientific management methods, etc. \\
\hline $\mathrm{N} 1$ & Weak team building & Unclear objectives or tasks; inappropriate structure of team members, etc. \\
\hline
\end{tabular}

\section{TRACEABILITY ANALYSIS ON SAFETY ACCIDENT OF SHIP MAINTENANCE}

Based on the safety analysis framework in Fig. 1, after classifying causation models and causes, it is necessary to carry out the traceability analysis of "effect-cause", analyze and find out the possible causes and prepare the "effect-cause traceability list", in order to repeatedly analyze and search for the possible causes and finally determine the root cause. In Table 3, each line takes a cause category as the effect, in order to list the possible general causes (indicated by code in the $3^{\text {rd }}$ column) and specific causes (in the $4^{\text {th }}$ column) and present the effectcause linked groups. The specific cause can be taken as root cause, while the general cause can be regarded as effect. The corresponding column is discovered in the table and then connected to the next effect-cause linked group. By tracing in this way, a series of effect-cause links are obtained. The causes represented by A1, D2, F1, G1 and L1 in the table are the effects without specific causes. Table 4 gives the possible basic causes for each causation model. Table 3 and Table 4 become the basis for the traceability analysis of root case, which is started from causation model.

If an accident has happened during ship maintenance, experts are responsible for surveying and analyzing the accident and concluding the expansion process of such accident. One or several safety incidents may exist in the expansion process of an accident. To find out the root cause for a safety incident, traceability analysis can be carried out by employing "effect-cause traceability list" and "basic cause list of causation model". The specific procedure is as follows:

Step1: Determine the category of error model based on the appearance of safety incident;

Step2: Allow experts to select several possible causes as the start of traceability analysis based on the basic cause list of causation model in Table 4 and the basic condition of the incident;

Step3: Take each branch cause as the effect, identify a line in the effect-cause traceability list (see Table 3), allow experts to select the possible general causes and specific causes based on the specific condition of the incident, and stop the analysis if no reasonable cause can be found; 
Table 3. Effect-Cause Traceability List

\begin{tabular}{|c|c|c|c|}
\hline Code & Effect & General Cause & Specific Cause \\
\hline $\mathrm{A} 2$ & Poor physical conditions & $\mathrm{G} 1, \mathrm{H} 1$ & Poor health condition, tiredness and other poor physical conditions \\
\hline B1 & $\begin{array}{l}\text { Negative psychological } \\
\text { factors }\end{array}$ & $\begin{array}{l}\mathrm{G} 1, \mathrm{H} 1, \mathrm{~J} 1, \mathrm{~J} 2 \\
\mathrm{~K} 1, \mathrm{~N} 1\end{array}$ & $\begin{array}{l}\text { Negative environment or motive of work, nerve, blind pursuit, } \\
\text { conformity and other psychological conditions due to personal issues }\end{array}$ \\
\hline $\mathrm{C} 1$ & $\begin{array}{l}\text { Lack of knowledge and } \\
\text { skills }\end{array}$ & $\mathrm{J} 1$ & Insufficient experience, lack of training, knowledge and skills \\
\hline $\mathrm{C} 2$ & $\begin{array}{l}\text { Bad attitude toward work } \\
\text { and habits }\end{array}$ & $\mathrm{B} 1, \mathrm{I} 1, \mathrm{~K} 1, \mathrm{~J} 2$, & Poor personal quality, bad work habits or poor attitude toward work \\
\hline D1 & Fatal equipment fault & F1, G1, & Quality problems of equipment \\
\hline E1 & Insufficient protection & $\mathrm{A} 4, \mathrm{C} 2$ & $\begin{array}{l}\text { Incomplete or defective protective devices, insufficient or defective } \\
\text { personal protection articles, e.g. protective clothes and gloves, etc. }\end{array}$ \\
\hline E2 & Improper use of tools & G1 & aging, expiration or delayed replacement of tools \\
\hline $\mathrm{G} 2$ & Lack of safety warnings & I1 & $\begin{array}{l}\text { No, obscure, unclear or misguiding signs including safety operating } \\
\text { procedures and warnings, etc. }\end{array}$ \\
\hline $\mathrm{H} 1$ & $\begin{array}{l}\text { Improper arrangement of } \\
\text { task/operation }\end{array}$ & $\begin{array}{l}\mathrm{C} 1, \mathrm{~K} 1, \mathrm{~L} 1 \\
\mathrm{M} 1, \mathrm{~N} 1\end{array}$ & $\begin{array}{l}\text { Limited level of knowledge and experience, Excessive workload, long- } \\
\text { term operation, change of operation or start of new operation and shift } \\
\text { change, etc. }\end{array}$ \\
\hline I1 & Lack of safety culture & $\mathrm{J} 2, \mathrm{~L} 1$ & $\begin{array}{l}\text { Leaders' lack of knowledge of and poor attitude toward safety, } \\
\text { people's weak awareness of and poor attitude toward safety, }\end{array}$ \\
\hline $\mathrm{J} 1$ & Lack of training about skills & L1 & $\begin{array}{l}\text { No corresponding training mechanism and trainings within an } \\
\text { organization }\end{array}$ \\
\hline $\mathrm{J} 2$ & Lack of safety training & I1, L1 & $\begin{array}{l}\text { Weak awareness of and poor attitude toward safety and low degree of } \\
\text { team recognition }\end{array}$ \\
\hline $\mathrm{K} 1$ & $\begin{array}{c}\text { Loose and unscientific } \\
\text { supervision and management }\end{array}$ & $\begin{array}{l}\mathrm{B} 1, \mathrm{C} 2, \mathrm{I} 1, \mathrm{~L} 1, \\
\mathrm{~N} 1\end{array}$ & $\begin{array}{l}\text { Insufficient fairness and completeness of supervision system; poor } \\
\text { execution of supervision and management }\end{array}$ \\
\hline M1 & Decision-making mistakes & $\begin{array}{l}\mathrm{A} 1, \mathrm{~A} 2, \mathrm{~A} 3, \\
\mathrm{~A} 4, \mathrm{~B} 1, \mathrm{C} 1, \mathrm{~L} 1\end{array}$ & $\begin{array}{l}\text { Management personnel's improper arrangement of working hours and } \\
\text { workers, unreasonable allocation of tasks and unscientific management } \\
\text { methods, etc. }\end{array}$ \\
\hline N1 & Weak team building & $\mathrm{I} 1, \mathrm{~L} 1$ & $\begin{array}{l}\text { Unclear objectives or tasks; inappropriate structure of team members; } \\
\text { lack of understanding and trust among team members, etc. }\end{array}$ \\
\hline
\end{tabular}

Step4: Stop analyzing any branch of specific cause, return to step 3 for any branch of general cause and repeat steps 3 and 4 . Through this cycle, a series of cause-effect links can be obtained. The last cause of each branch link will be a possible root cause of the safety incident.

Table 4. Basic Cause List of Causation Model

\begin{tabular}{|c|c|c|}
\hline \multicolumn{2}{|c|}{ Causation Model } & General Cause \\
\hline \multirow{4}{*}{$\begin{array}{l}\text { Human Factor } \\
\text { Causation } \\
\text { Model }\end{array}$} & Negligence & $\begin{array}{l}\mathrm{A} 1, \mathrm{~A} 2, \mathrm{~B} 1, \mathrm{C} 1, \mathrm{C} 2, \mathrm{G} 1, \\
\mathrm{G} 2, \mathrm{~K} 1\end{array}$ \\
\hline & Omission & $\mathrm{A} 2, \mathrm{C} 1, \mathrm{C} 2, \mathrm{G} 1, \mathrm{~K} 1$ \\
\hline & Wrongness & $\mathrm{A} 1, \mathrm{~A} 2, \mathrm{~B} 1, \mathrm{M} 1$ \\
\hline & Violation & $\mathrm{A} 1, \mathrm{~A} 2, \mathrm{~B} 1, \mathrm{C} 1, \mathrm{C} 2, \mathrm{~K} 1$ \\
\hline \multirow{3}{*}{$\begin{array}{l}\text { Object Factor } \\
\text { Causation } \\
\text { Model }\end{array}$} & $\begin{array}{l}\text { Equipment } \\
\text { Defects }\end{array}$ & D1, D2, \\
\hline & Tool Defects & $\mathrm{E} 1, \mathrm{E} 2$ \\
\hline & Energy Transfer & $\mathrm{F} 1$ \\
\hline \multirow{2}{*}{$\begin{array}{l}\text { Environmental } \\
\text { Factor } \\
\text { Causation } \\
\text { Model }\end{array}$} & $\begin{array}{l}\text { Hostile } \\
\text { Environment }\end{array}$ & $\mathrm{G} 1, \mathrm{G} 2$ \\
\hline & $\begin{array}{l}\text { Organizational } \\
\text { Impacts }\end{array}$ & $\begin{array}{l}\mathrm{H} 1, \mathrm{I} 1, \mathrm{~J} 1, \mathrm{~J} 2, \mathrm{~K} 1, \mathrm{~L} 1, \\
\mathrm{M} 1, \mathrm{~N} 1\end{array}$ \\
\hline
\end{tabular}

\section{CONCLUSION}

This paper straightens out and analyzes the causes for accident and their relations based on the theories of accident causation and hazard, and proposes a safety analysis method as a practical and effective tool for safety analysis during ship maintenance. The method is employed to analyze the shortcomings of the scenario based on the traceability analysis of the causes for safety accident and ascertain the root causes of the incident, in order to develop the effective preventive strategies and corrective actions and effectively prevent and reduce the occurrence of safety accident.

\section{REFERENCES}

[1] Occupational health and safety management systemGuidelines for the implementation of OHSAS 18001:2007. OHSAS 18002:2008, 2008.

[2] Fan Yunxiao and Luo Yun. System Safety Engineering. Beijing: Chemical Industry Press, 2009.

[3] Li Xiangmao, Tang Wenyong and Zhang Shengkun. Hazard sources risk assessment of ship's fire and explosion accidents. Chinese Journal of Ship Research, 2008, 3 (2): 21-26. 